Revista de Estudios Histórico-Jurídicos

[Sección historia del derecho europeo]

XLIII (Valparaíso, Chile, 2021)

[pp. 355-381]

\title{
Historia de Un PRECEDENTE FALLIDO: EL TRIBUNAL Supremo ESPAÑOL Y LA SOCIEDAd DE RESPONSABILIDAd LimitadA EN EsPAÑa (1919-1953)*
}

[History of a failed precedent: The Supreme Court of Spain and the limited liability company in Spain (1919-1953)]

\author{
Susana MARTínEZ-RodrígueZ** \\ Universidad de Murcia, España
}

\section{Resumen}

La sociedad de responsabilidad limitada fue una de las innovaciones más importantes en materia de sociedades del siglo XX, y resultó clave en el desarrollo económico contemporáneo. En España esta figura se introdujo a partir de 1919, sin una ley propia, contrariamente a lo usual en un país con un modelo de derecho continental. Cuando finalmente se aprobó

\begin{abstract}
The private limited liability company was one of the essential innovations in 20th-century companies and was vital in contemporary economic development. In Spain, this legal form was adopted since 1919, without its own bill, contrary to the usual in a country with a model of continental law. When the law was finally approved (1953), it did not consider the
\end{abstract}

* La autora agradece al Archivo General de la Administración de Alcalá de Henares (Madrid) su colaboración a través en un convenio institucional firmado con la Universidad de Murcia (Convenio de Colaboración entre el Ministerio de Educación, Cultura y Deporte y la Universidad de Murcia para la reproducción de documentos que se custodian en el Archivo General de la Administración, 2013) que permitió la reproducción de parte del material original utilizado en esta investigación. Versiones previas de la investigación fueron presentadas en el $A B H / G U G$ : Annual Conference of the Association of Business Historians - German GesellSchaft fur Unternehmensgeshichte (University of Humboldt-Berlin, 2016) y World Economic History (MIT-Boston, 2018). Porciones de la misma devienen de una línea de investigación conjunta desarrollada con T. W. Guinnane (Yale University), quien además aportó valiosos comentarios. Esta investigación se ha realizado en el marco del Proyecto RTI 2018-093884-B-100 financiado por Fondos Feder, Aie, y Ministerio de Ciencia, Innovación y Universidades de España. Por último, se dan efusivas gracias a los dos árbitros científicos y al editor de la revista, cuyas sugerencias han mejorado notablemente el artículo original. La responsabilidad es, como corresponde, exclusiva de la autora.

** Profesora Titular de Historia e Instituciones Económicas, Universidad de Murcia. Correo electrónico: susanamartinezr@um.es. ORCID 0000-0002-0710-6030. 
una ley (1953), ésta no tuvo en consideración los supuestos que el Tribunal Supremo había articulado durante los 30 años previos. A partir del análisis de fuentes primarias y la construcción de una base única de Sentencias del Tribunal Supremo este artículo analiza las circunstancias por las que el precedente creado por la más alta instancia de justicia constituyó un precedente débil, y por qué impactos exógenos, como fue la aprobación de una ley por parte del legislativo, lo ignoraron.

Palabras clave

Precedente legal - Sentencias del Tribunal Supremo - sociedad de responsabilidad limitada. assumptions that the Supreme Court had articulated during the previous 30 years. Based on the analysis of primary sources and the construction of a unique base of Judgments of the Supreme Court, this paper analyzes the circumstances for which the precedent created by the highest court of justice constituted a weak precedent, and why exogenous shocks, such as the legislative approval of a law, ignored it.

\section{Key Words}

Legal precedent - judgments of the Supreme Court - private limited liability company.

RECIBIDO el 30 de noviembre de 2019 y ACEPTADO el 26 de agosto de 2020

\section{INTRODUCCIÓN}

La sociedad de responsabilidad limitada es una de las innovaciones más importantes en materia de sociedades del siglo XX. Su popularidad obedece a que permitió a los empresarios acceder a ventajas organizativas anteriormente reservadas a las sociedades anónimas, pero sin asumir su costosa administración ${ }^{1}$. De origen europeo y continental, la sociedad de responsabilidad limitada se plasmó en nuevas leyes, recogiendo las demandas de empresarios, y el deseo del legislador por introducir nuevos instrumentos legales que estaban promoviendo la actividad económica en los países más desarrollados. Este artículo analiza un aspecto particular de la implantación de dicha forma legal en España, si bien la investigación realizada permite extraer conclusiones de mayor calado sobre la figura en sí, y sobre el sistema legal de derecho continental.

La primera ley alusiva a la sociedad de responsabilidad limitada en España aparece en 1953, pero ya entonces llevaba varias décadas funcionando con regularidad, pues en el Reglamento del Registro Mercantil (1919) se explicita que este tipo de figura societaria sí se puede registrar, siempre y cuando cumpla con las características requeridas. Durante casi 30 años la jurisprudencia española dio por válido que, ante la falta de leyes propias, la sociedad de responsabilidad limitada se asimilaría a una sociedad colectiva. Era una decisión basada en que la sociedad colectiva era el tipo de sociedad de mayor antigüedad y que mayor protección ofrecía a terceros. También era una decisión que partía de una clara anomalía: que la sociedad de responsabilidad limitada no tenía una ley propia. Notarios,

\footnotetext{
${ }^{1}$ Guinnane, Timothy W.; Harris, Ron y Lamoreaux, Naomi, Contractual Freedom and Corporate Governance in Britain in the Late Nineteenth and Early Twentieth Centuries, en Business History Review, 91/2 (2017), pp. 227-277.
} 
abogados y jueces respetaron esta práctica, y así quedó escrito en la literatura, apelando a la sencillez, a las costumbres y a las decisiones del Tribunal Supremo sobre esta figura. Sin embargo, la Ley de Sociedades de Responsabilidad Limitada de 1953 con claridad establecía que la sociedad de responsabilidad limitada tendría como norma accesoria la Ley de Sociedades Anónimas (1951). Los hechos descritos evidencian un dato objetivo, y es que el legislativo ignoró las disposiciones y actuaciones del Tribunal Supremo. La hipótesis de investigación construye una narrativa que explica el porqué de estos hechos: el precedente del Tribunal Supremo era débil, y por eso fue ignorado a la hora de aprobar una nueva ley.

La argumentación para demostrar la hipótesis se plantea de la siguiente forma: ¿Por qué fue tan sencillo eliminar casi 30 años de decisiones, dictámenes, sentencias, donde dominaba la interpretación de que la sociedad de responsabilidad limitada se asemejaba más a una sociedad colectiva? La respuesta implica analizar el significado del precedente legal. Conocido es que la ley del precedente, stare decisis, es la base angular del sistema legal anglosajón ${ }^{2}$. Esto significa que las decisiones de los jueces para crear leyes consideran, sin excepción, fallos de casos similares previos. La doctrina del precedente también es un elemento de la evolución jurisprudencial en el sistema legal civil, o derecho continental (jurisprudence constance $)^{3}$, pero con poca relevancia hasta finales del XX, cuando empieza a recibir la influencia del sistema legal anglosajón y la consideración del principio de igualdad en la aplicación de la ley. Si bien en la justicia de la Unión Europea no existe una teoría articulada que en sí que avale el precedente, el Tribunal Superior de la Unión Europea, en efecto, parece remitir a sentencias previas, esto es, precedentes, como un referente a la hora de aplicarlas o mencionarlas en casos posteriores ${ }^{4}$.

Históricamente, en los países con un modelo jurídico inspirado en la tradición romana, se ha considerado el precedente un elemento con relevancia relativa, y por lo general no vinculante 5 . En este artículo se estudia un caso que evidencia la debilidad del precedente, hasta el punto que la nueva legislación lo ignora. En cuanto al método de la investigación, se ha elaborado una base novedosa de sentencias del Tribunal Supremo para la etapa 1918-1964 en las que (al menos) una de las partes litigantes era una sociedad de responsabilidad limitada. Los dos principales resultados obtenidos son: i) que el Tribunal Supremo, en la mayor parte de los casos, no se pronuncia sobre la sociedad de responsabilidad limitada, ni sobre su naturaleza o cualidades, dado que en el ordenamiento jurídico español la existencia de una sociedad mercantil significa que ha verificado un

${ }^{2}$ Parisi, Francesco; DePoorter, Ben, Legal precedents and judicial discretion, en Rowley, Charles; SCHNEIDER, Friedrich (eds.), Encyclopedia of public choice (Amsterdam, 2003), pp. 341-343

${ }^{3}$ Iturralde, Victoria, Precedente Judicial, en Eunomia. Revista en la Cultura de la Legalidad, 4 (2003), pp. 194-201.

${ }^{4}$ McAuliffe, Karen, Precedent at the Court of Justice of the European Union: The Linguistic, en Aspect en Current Legal Issues, 15 (2013), pp. 483-493 [https://www.openaccessgovernment.org/ linguistic-precedent/66866/]

${ }^{5}$ Un interesante estudio sobre un uso particular del precedente se encuentra en GARVEY Algero, Mary, The Sources of Law and the Value of Precedents: A Comparative and Empirical Study of a Civil Law State in a Common Law Nation, en Lousiana Law Review, 65/2 (2005), pp. 775-822. 
proceso que el Registro Mercantil ha considerado válido; ii) en aquellos casos que se pronuncia, la asimila a una sociedad colectiva y respeta este precedente en posteriores dictámenes.

Un segundo objetivo particular del artículo ha sido analizar el carácter dinámico de la ley y sus instituciones; la separación de poderes entre el legislativo y el judicial; y el principio de coherencia del Tribunal Supremo para mantener su credibilidad, al ser fiel a su precedente. Otra aportación es el debate sobre la jurisprudencia mercantil como fuente del derecho y el análisis detallado de un grupo de sentencias del Tribunal Supremo que muestran la cercanía que los jueces de la más alta instancia encontraban entre la sociedad de responsabilidad limitada y la sociedad colectiva.

La organización del artículo es como sigue. Tras esta introducción en la que se exhiben los elementos básicos de la investigación (contextualización, hipótesis, objetivos, método y fuentes), la primera parte de la sección I, reconstruye los elementos del marco jurídico de la sociedad de responsabilidad limitada con anterioridad a la ley de 1953, mostrando que si bien no existía una ley propia sí un conjunto de leyes supletorias que garantizaban jurídicamente el funcionamiento de la sociedad de responsabilidad limitada. En este epígrafe se presta especial atención al análisis del discurso de los principales juristas contemporáneos. La sección I.1 analiza en profundidad las fuentes de la ley, proporcionando una visión de amplio espectro. Primero, se reflexiona sobre el papel de la jurisprudencia general en el sistema legal continental para, seguidamente, estudiar el valor de la jurisprudencia como fuente del derecho a través de los manuales de derecho mercantil más relevantes de la etapa 1890-1940. La última parte de la sección I.2, describe las fuentes archivísticas que serán analizadas a continuación, y cómo se ha confeccionado la base de sentencias del Tribunal Supremo. La sección II, dividida en cinco apartados, aborda un detallado análisis de aquellas sentencias relevantes para crear doctrina sobre la sociedad de responsabilidad limitada, las dificultades en las primeras traducciones del término de sociedades extranjeras registradas en España, la flexibilidad del marco legal, las características de la sociedad de responsabilidad limitada que dictamina el Tribunal Supremo, su proximidad con la sociedad colectiva, y la narración de cómo se aprueba la sociedad de responsabilidad limitada y porqué se ignora la experiencia y el hacer coherente del Tribunal Supremo. La sección II.5, presenta un ejercicio intelectual pocas veces posible: analiza qué elementos incluyó la nueva ley que respetaban el precedente previo, y cuál fue la valoración recibida por los contemporáneos. Una reflexión final y corolarios cierran el trabajo de investigación.

\section{I. ¿EXISTÍA INSEGURIDAD JURÍDICA PARA HACER USO DE LA SOCIEDAD DE RESPONSABILIDAD LIMITADA EN LA ETAPA PRE-LEGISLATIVA (1919-1953)?}

En tiempos de la aprobación de la Ley de Sociedades de Responsabilidad Limitada varios coetáneos advirtieron de la p e li g r o s i d a d de una figura que carecía de regulación ${ }^{6}$, porque consideraban que este vacío legal podía dar lugar

${ }^{6}$ Salvador Gullón, Pablo; Salvador Gullón, Hilario, Fundación de la Sociedad Limitada, en 
a fraudes de ley. Aunque no existía una ley propia para la sociedad de responsabilidad limitada, sí había un marco jurídico en el que insertarla de forma correcta. El art. 122 del Código de Comercio contemplaba la posibilidad de que se crease cualquier tipo de sociedad no estrictamente tipificada en el código, siempre y cuando respetase la ley. Esta interpretación del artículo fue manifestada en los debates celebrados en las Cortes antes de la aprobación del Código de Comercio de $1885^{7}$. Nada imposibilitaba, entonces, que desde 1886 hubiera sociedades de responsabilidad limitada, pero, aunque diferentes autores apuntaron a la existencia de sociedades que, en la práctica funcionaban como éstas ${ }^{8}$, lo cierto es que los empresarios no se interesaron por esta figura hasta que se pudo registrar en el Registro Mercantil ${ }^{9}$. El art. 108 del Reglamento del Registro Mercantil concedía dos características a la sociedad de responsabilidad limitada: i) la responsabilidad limitada para los socios, y ii) la obligatoriedad de incluir el acrónimo SL en el nombre de la sociedad. Esta regulación facilitó un instrumento de comunicación con la Administración que garantizaba el funcionamiento correcto de la sociedad de responsabilidad limitada porque la sujetaba al Código de Comercio.

La sociedad de responsabilidad limitada gozó a partir de 1920 de gran popularidad y éxito. La información estadística para la etapa 1920-1953 muestra un ascenso constante hasta constituir el $47,58 \%$ de todas las sociedades registradas (619 sociedades de responsabilidad limitada sobre un total 1.301 sociedades mercantiles); en el Censo de Sociedades de 1950 el porcentaje efectivo de sociedades de responsabilidad limitada en la economía española era de 30,31\% (6515 sociedades de responsabilidad limitada de un total de 21.497 sociedades mercantiles $)^{10}$.

Desde este momento, la sociedad de responsabilidad limitada en España ocupó el lugar tanto de la sociedad anónima como de la sociedad colectiva, y fue especialmente popular entre las empresas de pequeño y mediano tamaño. En la práctica tenía un tamaño similar a la sociedad colectiva, pero desde un principio mostró distintivas características en su estructura, como el dominio de socios sin vínculos familiares entre sí. En casi un tercio de las sociedades colectivas todos los socios compartían lazos familiares, una proporción mucho más elevada que en cualquier otra figura legal. Por otro lado, en las sociedades comanditas y las sociedades de responsabilidad limitada era mucho más frecuente que, aun en el caso

Revista Jurídica de Cataluña, 70 (1953), p. 529; PÉrez SERrano, Nicolás, La proyectada reforma del Código de Comercio. Compañias Anónimas y limitadas, en Revista Derecho Privado, 158 (1927) pp. 3 y ss.

${ }^{7}$ Sesión de Cortes, miércoles 24 de enero de 1883, Diario de las Sesiones de las Cortes. Congreso de los Diputados (1883), XXIX, pp. 593-617.

${ }^{8}$ Castellar, Enrique, Sociedades Mercantiles a Responsabilidad Limitada, en Revista Jurídica de Cataluña, 1 (1895), pp. 436-441.

${ }^{9}$ Guinnane, Timothy W.; Martínez-Rodríguez, Susana, Choice of the Enterprise form: Spain 1886-1936, en Journal of Law, Economics and Organization, 34/1 (2018), pp. 1-26.

${ }^{10}$ Información extraída de la base de datos propia configurada a partir de los Anuarios de la Dirección General del Registro y el Notariado (1920-1953). La información del Censo de Sociedades y empresas (1951) consideraba para el cómputo el número de sociedades anónimas (11053), sociedades en comandita (349), sociedades colectivas (3580) y sociedades de responsabilidad limitada (6515). 
de haber familiares, estuvieran acompañados de otros socios ajenos a los vínculos de sangre ${ }^{11}$, lo que apunta a la búsqueda de inversores fuera de la propia familia.

Otro instrumento legal que dio cobertura a la sociedad de responsabilidad limitada fue el derecho positivo, emanado del Tribunal Supremo y de la Dirección General del Registro y el Notariado. Ambas instituciones manifestaron que la obligación de legislar la sociedad de responsabilidad limitada correspondía al legislador. El objetivo que guiaba las actuaciones de la Dirección General del Registro y el Notariado era ofrecer el marco más idóneo para el uso de la sociedad de responsabilidad limitada a los empresarios. Su perfil dinámico intenta recoger el pulso de la ley en todas sus manifestaciones, y su contacto directo con la realidad empresarial le permitía adaptarse con rapidez a sus necesidades ${ }^{12}$.

Sobre las opiniones del Tribunal Supremo no existe ningún trabajo realizado hasta el momento. La guía directriz del Tribunal Supremo era efectuar una correcta interpretación de la ley escrita. Y al no existir una ley escrita particular de la sociedad de responsabilidad limitada, hacer una interpretación dentro del marco del código mercantil. El presente estudio desvela que, contemplando esta máxima, el Tribunal Supremo fue coherente en sus dictámenes (1918-1956). Siempre consideró a la sociedad de responsabilidad limitada como una sociedad personalista, más cercana a la sociedad colectiva y a la sociedad en comandita que a la sociedad anónima, por lo tanto, el derecho aplicable eran las disposiciones del Código de Comercio alusivas a las sociedades colectivas.

El número de sentencias del Tribunal Supremo en las que entra a debatir y sentar doctrina sobre la sociedad de responsabilidad limitada es muy reducido. Lo escaso, como se evidenciará más adelante, no eran los casos que llegaban al Tribunal Supremo donde una de las partes era una sociedad de responsabilidad limitada, sino aquellos casos en los que el ponente del Supremo apuntaba algún comentario doctrinal o sobre la naturaleza de la sociedad de responsabilidad limitada. En España la decisión de si una sociedad era o no válida legalmente se determinaba en el Registro Mercantil, y su inscripción marcaba el inicio de la vida de la sociedad mercantil. Este es un aspecto fundamental que permite explicar cómo pudo proliferar dicha figura (y en particular el éxito que alcanzó) sin contar con una ley propia. Paradójicamente hay casos en la literatura internacional, como el reflejado a continuación, en el que las novedades societarias fracasaron porque no contaban con evidencias de casos reales, aunque contaban con una ley: a finales del XIX en Estados Unidos, Pensilvania, se aprobó un nuevo tipo de sociedad que encajaría con un precedente de la sociedad de responsabilidad limitada ${ }^{13}$. Aunque la ley era clara en cuanto a las características de la nueva figura, los problemas sobre su legalidad aparecieron cuando los jueces declararon su no legalidad, porque no encajaba con las figuras conocidas. En Pensilvania,

${ }^{11}$ Guinnane, Timothy W.; Martínez-Rodríguez, Susana, Instructions not included: Spain's Sociedad de Responsabilidad Limitada, 1919-1936, en European Review of Economic History, 22 (2018), pp. 462-482.

${ }^{12}$ Martínez-Rodríguez, Susana, Creating the sociedad de responsabilidad limitada: The Use of Legal Flexibility in the Spanish Company Law, 1869-1953, en Business History Review, 90/2 (2016), pp. 227-249.

${ }^{13}$ Guinnane, Timothy W. et al, cit. (n. 1). 
la falta de seguridad jurídica -pues los jueces podrían declarar, y declararon, no legal este tipo de sociedad- provocó el abandono de la figura. Por el contrario, en España el marco legal determinaba que si el Registro Mercantil, tras cotejar las características de la sociedad de responsabilidad limitada, la consideraba correcta, era muy difícil que otra instancia de justicia cuestionase este hecho, porque iba en contra de la legalidad vigente.

La situación vivida con la aprobación de la ley de 1953 y el precedente de la sociedad de responsabilidad limitada presenta similitudes con el siguiente modelo teórico, cuya presentación ayuda a contextualizar el caso a estudio. Fon y Parisi construyeron un modelo sobre los precedentes en la tradición legal romanista en el que la variable estabilidad y la variable cambios en las reglas (o leyes) estaba determinado por varios factores como el volumen existente de precedentes legales -es decir, una métrica de los precedentes- o el número reciente de sentencias sobre una situación o tópico particular ${ }^{14}$; otra variable importante a considerar era el impacto institucional que podía derivarse de un elemento exógeno. Un ejemplo de impacto exógeno era una nueva ley que afectara la veracidad del precedente. Para la sociedad de responsabilidad limitada, por las razones que se explicarán, existía un surtido de decisiones sobre la sociedad de responsabilidad limitada muy pequeño; y además que éstas habían sido cuestionadas por algunos contemporáneos. La Ley de Sociedades de Responsabilidad Limitada fue (en los términos de Fon y Parisi) un impacto exógeno que destruyó el -débil-precedente creado, porque apuntaló que la figura cercana a la sociedad de responsabilidad limitada era la sociedad anónima, y no la sociedad colectiva.

La siguiente sección explora las raíces de dicha ineficiencia, fundamentada en que la jurisprudencia en España no es fuente de la ley mercantil.

\section{Las fuentes del derecho en España}

La expresión fuentes del derecho no debe tomarse como un axioma universal. El análisis de cinco manuales profusamente utilizados en derecho mercantil a lo largo del periodo temporal de estudio muestra que la consideración de la jurisprudencia, como fuente del derecho mercantil, fue decreciendo. El valor a la baja de las sentencias del Tribunal Supremo es un buen elemento para contextualizar: i) una jurisprudencia que de forma coherente y continuada había defendido la cercanía entre la sociedad de responsabilidad limitada y la sociedad colectiva; ii) las dudas que suscitaban entre algunos juristas las decisiones doctrinales del Tribunal Supremo sobre la sociedad de responsabilidad limitada y su cercanía con la sociedad colectiva; iii) que la ley de 1953 estuviera más próxima a la sociedad anónima que a la sociedad colectiva.

El periodo analizado de la doctrina mercantil española del siglo XIX y XX es comparativamente inferior en calidad a la doctrina española del XVI-XVIII (la Edad de Oro de la literatura jurídico mercantil ${ }^{15}$. Y comparada con el resurgir en Europa de los estudios de esta disciplina del XIX. En España destacó en el

\footnotetext{
${ }^{14}$ Fon, Vincy; PARISI, Francesco, Juditial precedents in civil law, en Internatinal Review of Law and Economics 26/4 (2006), pp. 519-535.

${ }^{15}$ Menéndez, Aurelio, Sobre la moderna Escuela Española de Derecho mercantil (Madrid, 1993 [2016]), pp. 23-24.
} 
primer tercio del XIX la figura de Sáinz de Andino, padre del código mercantil de 1829, y de otros textos legales relevantes ${ }^{16}$. La obra de los mercantilistas posterior a 1885 fue especialmente oscura, retomando de nuevo el impulso en el primer tercio del XIX ${ }^{17}$.

El primer jurista a considerar es R. Martí de Eixalá (1870 [1848]), quien declara que las fuentes del derecho mercantil en España son la legislación mercantil, los usos y prácticas comerciales y la jurisprudencia ${ }^{18}$. Señala sobre la jurisprudencia que "los códigos modernos necesitan este complemento para la eficacia de su precepto, pues, dada su forma aforística, no se perciben a primera vista las dificultades de su aplicación: la jurisprudencia viene a llenar las lagunas que dejan los códigos" ${ }^{19}$. Aunque cuando este autor publicó su obra regía el Código de Comercio de 1829, continuó siendo profusamente citado tras la aprobación del Código de Comercio (1885), y por este motivo se referencia.

P. Estasén fue pionero en el estudio de la sociedad de responsabilidad limitada, con un tratado de sociedades mercantiles. En 1890, P. Estasén reafirmaba lo dicho por R. Martín de Eixalá -al que cita- sobre las fuentes del derecho y su prelación ${ }^{20}$. En otra obra, sin embargo, añadía que "tiene en lo mercantil la costumbre una gran fuerza puesto que el derecho mercantil es esencialmente consuetudinario"21. Esta opinión se fundamentaba en un precepto escrito: el art. 2 del Código de Comercio (1885) dictamina que "a falta de disposición determinante de éste y de los usos observados generalmente en cada plaza se regirán por las del derecho común" (en el Código de Comercio de 1829 no figuraba este artículo).

El tercer autor de referencia es L. Benito. Para este jurista, las leyes por las que se rige el comercio son el código de comercio, leyes especiales anteriores y posteriores que lo complementan, las leyes del derecho común y las leyes mercantiles extranjeras - de las que proporciona un prolijo detalle ${ }^{22}-$. En cuanto a los usos y costumbres, el autor valora positivamente su consideración en el ámbito mercantil $1^{23}$. Considera L. Benito jurisprudencia, en general, a "todas aquellas reglas de derecho que, dictadas por un tribunal para resolver un caso particular, se aplican por el mismo u otros tribunales a casos análogos, adquiriendo de este modo carácter estable y general' ${ }^{24}$. Por lo tanto, se destaca la importancia del precedente, ya que de la habilidad de la corte para justificar sus decisiones y ser coherente en sus sucesivas sentencias con las previas, dependería su reputación. Tras esta aseveración general, apunta el

${ }^{16}$ Diccionario bibliográfico electrónico de la Real Academia de Historia. Real Academia de la Historia [http://dbe.rah.es/] (voz: Sáez de Andino).

${ }^{17}$ Menéndez, Aurelio, cit. (n. 15), pp. 23-24.

${ }^{18}$ Martín de Eixala, Ramón, Instituciones de derecho mercantil de España (5 a ed. puesta al día por M. Durán y Bas. Barcelona-Madrid, [1848] 1870), p. 108.

${ }^{19}$ Ibíd, p. 113.

${ }^{20}$ Estasén, Pere, Fuentes del derecho en Instituciones de derecho mercantil (Madrid, 1890-1907), II, p. 194.

${ }^{21}$ Ibíd, pp. 197-198.

${ }^{22}$ Benito, Lorenzo, Manual de derecho mercantil de España y de las principales naciones de Europa y América (Valencia, 1924), I, pp. 216-236.

${ }^{23}$ Ibíd, pp. 237-256.

${ }^{24}$ Ibíd, p. 256. 
jurista que, en España, el concepto en sí de jurisprudencia era mucho más parco: "pues solo se aplica este nombre a las resoluciones del Tribunal Supremo de Justicia, repitanse o no en distintos fallos, y las del Tribunal de lo Contencioso Administrativo. También son jurisprudencia las resoluciones de la Dirección General del Registro y el Notariado, recaídas en las consultas sobre inteligencia de la Ley Hipotecaria, y en los casos de oposición de los Registradores a inscribir documentos presentados a este efecto en los registros de la propiedad"25.

Sin embargo, ni el Código de Comercio (1885) ni el Código Civil (1889) vigentes citaban a la jurisprudencia entre las fuentes del derecho, y esto había generado un debate. Benito criticaba el silencio del legislador en este tema y afirmaba la validez de la jurisprudencia como fuente del derecho ${ }^{26}$. Entre las voces a favor cita a Blasco Constans (1885 [1902]), quien apoya su postura en el art. 6 del Código $\mathrm{Civil}^{27}$. Y entre las opiniones en contra destaca la de Álvarez del Manzano ${ }^{28}$.

El cuarto autor a considerar es J. Garrigues, quien según A. Menéndez inicia una nueva etapa de luz en la jurisprudencia mercantil española ${ }^{29}$. En 1936-1940 publicó Curso de derecho mercantil, obra de referencia en la evolución de la ciencia jurídico-mercantil española. Garrigues considera que las fuentes del derecho mercantil son ley, costumbre o uso, las mismas que las del derecho civil. La fuente primera del derecho mercantil es el código mercantil y las leyes especiales mercantiles. En cuanto a la costumbre, o uso, justifica J. Garrigues que h is tó ri c a m e n t e haya ocupado el primer rango en las fuentes del derecho mercantil. Esto obedecía a la propia naturaleza de los hechos económicos y que el derecho mercantil no nacía legislativamente, sino por la fuerza del uso ${ }^{30}$. En ningún momento de la discusión (sobre fuentes) se menciona la jurisprudencia.

R. Gay de Montella, coetáneo del anterior jurista, cuenta con una extensa obra específica sobre la sociedad de responsabilidad limitada. En su manual sobre el Código de Comercio, apunta que la jurisprudencia no es considerada fuente de ley mercantil por el Código de Comercio ${ }^{31}$. Pero reconoce el valor de las sentencias, en caso de fundamentar los recursos de casación frente al Supremo, e insiste en que deben ser fallos repetidos y en idénticas decisiones para que puedan ser (nuevamente) aplicables ${ }^{32}$.

La opinión y el criterio de los cinco autores analizados, cuyos manuales de derecho mercantil formaron a generaciones de jueces, notarios, registradores y abogados, evidencian una ponderación a la baja de la consideración de la jurisprudencia en los asuntos mercantiles, siendo su valor claramente inferior al de la tradición. Sus opiniones fueron relevantes e influyentes sobre qué grado de

${ }^{25}$ Ibíd.

${ }^{26}$ Ibíd, p. 259.

${ }^{27}$ Blanco Constans, Francisco, Estudios elementales de derecho mercantil según la filosofía, la historia y la legislación vigente en España y en las principales naciones de Europa y América (Madrid, 1901-1902, edición original 1885), I, p. 322.

${ }^{28}$ Alusión a la obra de Álvarez del Manzano, referenciada en BENITo, Lorenzo, cit. (n. 22) p. 358 .

${ }^{29}$ MenÉndez, Aurelio, cit. (n. 15), pp. 21-23; 32.

${ }^{30}$ Garrigues, Joaquín, Curso de derecho mercantil (Madrid, 1936-1940), p. 89.

${ }^{31}$ Gay de Montella, Rafael, El Código de Comercio Español (Barcelona, 1936) p. 19.

${ }^{32}$ Ibíd, p. 28. 
autoridad tenían las decisiones del Supremo en materia mercantil. Y esto es particularmente relevante en el estudio de la sociedad de responsabilidad limitada, donde apenas existe normativa positiva. En España, para la etapa analizada, la jurisprudencia tiene un valor relativo como fuente de consulta, pero nunca de ley. Una conclusión similar es la extraída para Francia en un análisis histórico del principio de precedente donde se señala que la única fuente legítima de la ley es la ley en sí misma, y en particular el código, y es este hecho el que niega a las cortes la facultad de hacer reglas que interfieran con la legislación ${ }^{33}$. La rotundidad en esta afirmación deviene de la etapa previa a la Revolución Francesa, en la que la opinión de los jueces estaba sometida a la voluntad real ${ }^{34}$.

\section{Las fuentes utilizadas: expedientes y sentencias del Tribunal Supremo}

El objetivo de esta sección es describir las fuentes empleadas para la compilación y análisis de las sentencias del Tribunal Supremo alusivas a sociedades de responsabilidad limitada. En España la recopilación de las sentencias del Tribunal Supremo apareció primero en la Gaceta de Madrid, también la colección Biblioteca Jurídica de la Revista General de Legislación y Jurisprudencia ha publicado las sentencias del Tribunal Supremo. Además, diferentes editoriales y autores han editado compendios de doctrina jurisprudencial sistematizada.

A partir de 1868 desaparece el tribunal especial sobre comercio y los casos relativos a sociedades pasan a ser resueltos por la justicia ordinaria, en las salas de lo civil. Cuando no existe acuerdo en la primera instancia, el litigante puede apelar a la Audiencia Provincial, y si disiente del resultado, y el caso cumple determinados parámetros, puede presentar recurso de casación ante el Supremo.

Existen algunos comentarios particulares a las Sentencias del Tribunal Supremo realizados por expertos juristas contemporáneos ${ }^{35}$, o en las revistas especializadas (Revista General de Legislación y Jurisprudencia, Revista de Derecho Privado). La poca información sobre el debate de la sociedad de responsabilidad limitada publicada en las sentencias evidencia la hipótesis que el estilo de las opiniones es deductivo. En general, el estilo de la jurisprudencia en España tiene un tono más deductivo que discursivo y esta influencia deviene de la teoría de la actividad jurídica considerada como una actuación silogística (así entendida durante el siglo XIX): los rudimentos de la sentencia se construyen indicando, primero, los hechos probados, luego los criterios legales que han sido aplicados en el caso; y por último la decisión final, deducida de $\operatorname{ambos}^{36}$.

Con el objetivo de confeccionar una muestra de sentencias lo más completa

${ }^{33}$ Troper, Michel y Grzegorczyk, Christophe, Precedent in France, en McCormick N. Deil; Summers, Robert S., Goodhart, Arthur L., Interpreting Precedents. A comparative Studies (London, 1997), p. 117.

${ }^{34}$ Ibíd, p. 130.

${ }^{35}$ Es el caso de Eizaga Gondra, Martín, Problemas actuales de la sociedad de responsabilidad limitada, en Revista de Derecho Mercantil, 2/4 (1946), pp. 83-105; TAulET, Enrique, Sociedad de responsabilidad limitada. Conferencia desarrollada por D._pronunciada el 19 de enero de 1946 (Valencia, Imprenta Diana, 1947); Rodríguez NAvarro, Manuel, Doctrinal mercantil del Tribunal Supremo (Madrid, 1948).

${ }^{36}$ Ruiz Miguel, Alfonso; Laporta, Francisco J., Precedent in Spain, en McCormick N. Deil; 
posible en esta investigación se ha revisado, además de las fuentes citadas al inicio de la sección, la información publicada en las sentencias de la Colección Legislativa de Jurisprudencia Aranz̧adi. Y el resultado de esta exhaustiva revisión fue ratificar que había muy pocos dictámenes que aludiesen a las sociedades de responsabilidad limitada. En este punto de la investigación se acometió una labor de archivo de envergadura: acudir a la fuente archivística que permitiera consultar los expedientes enteros, pues en el transcurso del caso quizá los magistrados podrían haber expresado algunas opiniones concretas sobre la sociedad de responsabilidad limitada. Se ha confeccionado una base única e inédita con la información de los expedientes originales del Tribunal Supremo custodiados en el Archivo General de la Administración de Alcalá de Henares (Madrid), formada por un conjunto de 96 expedientes comprendidos entre 1918-1964. Son todos los expedientes de casos ante el Tribunal Supremo que existen en esta localización con al menos una parte litigante siendo una sociedad de responsabilidad limitada ${ }^{37}$.

La base de datos contiene recursos de casación, que es un recurso extraordinario cuyo objetivo es la casación o firmeza de sentencia; o, en caso contrario, la anulación de la misma. La organización del Tribunal Supremo para el periodo de estudio estaba contenida, básicamente, en la Ley Provisional sobre Organización del Poder Judicial de 18 de septiembre de 1870, y la Ley Adicional a la Orgánica del Poder Judicial del 14 de octubre de $1882^{38}$. El Tribunal Supremo resolvería de forma exclusiva los recursos de casación: la Sala I resolvería los recursos de casación por infracción de ley, o doctrina legal (art. 1687), y la Sala III los demás recursos (art. 1688). Los 96 casos que componen la base de datos inicial, tal y como muestra el Cuadro 1, abarcan seis casuísticas. La mayor incidencia está en los casos de infracción de la ley -más de la mitad, 54-; y a gran distancia los de competencia (24 casos) e injusticia notoria (12 casos). Los casos de infracción de la ley son aquellos recursos que se fundamentan en la incorrecta interpretación de la ley. En los recursos de competencia la función del Tribunal Supremo es determinar qué juzgado es finalmente el competente. Los recursos de injusticia notoria tendrían su equivalente en lo que en la actualidad se denomina desahucios improcedentes. Acorde a la información proporcionada en el Cuadro 2, en 33 expedientes la sociedad de responsabilidad limitada es demandante, 54 en los que

Summers, Robert S.; Goodhart, Arthur L., Interpreting Precedents. A comparative Studies (Londres, 1997), p. 264.

${ }^{37}$ En el Archivo General de la Administración (Alcalá de Henares, Madrid) no existía, cuando se realizó la fase archivística de la investigación (2013-2014), ningún tipo de documentos o memorias anuales que clasifiquen de manera sistemática o/y periódica los expedientes, por lo que la selección se realizó de forma manual. En el Archivo Histórico Nacional hay otros expedientes que no hemos consultado. En este tipo de investigaciones las variables tiempo y recursos condicionan en demasía el alcance la misma.

${ }^{38}$ Muchos fueron los proyectos de la etapa, incluso una ley de bases, como la Ley de Bases del 31 de marzo de 1900, que apareció como apéndice del art. 17 de la Ley de Presupuestos de 31 de marzo de 1900. La Ley de Enjuiciamiento Civil (1881) dedica el Título XXI al recurso de casación (Título XXI: Del recurso de casación, art. 1686 a art. 1795). Información referenciada a través de LAsso, Juan Francisco, Crónica de la codificación española: organización judicial (Madrid, 1999), I, p. 202. 
es demandada, en cinco casos la sociedad limitada ocupa ambas posiciones (de demandante y demandada), y hay cuatro supuestos sin información al respecto. Cuando la sociedad de responsabilidad limitada no litiga con otra sociedad de responsabilidad limitada, suele hacerlo contra un individuo, o contra una sociedad anónima.

\section{Cuadro 1}

TIPOS DE CASACIÓN

\begin{tabular}{|c|c|}
\hline Tipo de recurso de casación & N. Casos \\
\hline Cuestión de Competencia & 24 \\
\hline Declaración de Pobreza & 1 \\
\hline Exequátuor & 1 \\
\hline Infracción de Ley & 54 \\
\hline Injusticia Notoria & 12 \\
\hline Recurso Queja & 4 \\
\hline $\mathrm{N}^{\circ}$. de casos & 96 \\
\hline
\end{tabular}

(Elaboración propia: base de datos propia de las "Sentencias del Tribunal Supremo sobre Sociedades de Responsabilidad Limitada - Archivo General de la Administración (Alcalá de Henares, Madrid)”).

\section{Cuadro 2}

\section{DisTRIBUCIÓN DEMANDANTES Y DEMANDADOS}

\begin{tabular}{|l|c|c|c|c|}
\cline { 2 - 5 } \multicolumn{1}{l|}{} & Demandante & Demandado & Ambos & Sin información \\
\hline $\begin{array}{l}\text { Sociedad de responsabilidad } \\
\text { limitada }\end{array}$ & 33 & 54 & 5 & \\
\hline Sociedad anónima & 11 & 6 & & \\
\hline Sociedad civil & 0 & 1 & & \\
\hline Mutualidad & 0 & 1 & & \\
\hline Sociedad Cooperativa & 0 & 1 & & \\
\hline Sociedad industrial Sociedad & 1 & 0 & & \\
\hline Sociedad Colectiva & 1 & 1 & & \\
\hline Gobierno & 1 & 0 & & \\
\hline Individuo & 31 & 23 & & \\
\hline & & & & \\
\hline No. casos: 96 & & & & \\
\hline
\end{tabular}

(Elaboración propia: base de datos propia de las "Sentencias del Tribunal Supremo sobre Sociedades de Responsabilidad Limitada - Archivo General de la Administración (Alcalá de Henares, Madrid)").

Otro elemento de interés es conocer la composición y el funcionamiento del Tribunal Supremo. El alto tribunal podía estar formado hasta por siete miembros (art. 317 de la Nueva Ley de Enjuiciamiento Civil). Uno actuaba como ponente: 
tras realizar el examen de las pruebas, proponía y redactaba las resoluciones que dictaba el tribunal, y a él se dirigían las partes. Entre la lista de ponentes de los casos a estudio hay juristas de reconocido prestigio, y otros que no cuentan con obra publicada.

Una vez realizadas las consideraciones descriptivas previas procede analizar cómo se han manejado los expedientes. La labor de revisión de los expedientes ha supuesto la lectura completa de los mismos. El objetivo era encontrar algún elemento, comentario, sugerencia, donde el letrado del Supremo manifestara su criterio sobre la sociedad de responsabilidad limitada, pronunciando una opinión particular. Aquellas sentencias que incluyen comentarios sobre la sociedad de responsabilidad limitada (su naturaleza, la falta de legislación, qué artículos del Código de Comercio sigue, si genera similitudes con otra sociedad, la inscripción de la sociedad de responsabilidad limitada en el Registro Mercantil, etc.), aportan muy poco apoyo documental para dictaminar que el Tribunal Supremo tuvo un papel activo en la definición de sociedad de responsabilidad limitada. De 96 expedientes revisados solo siete contienen comentarios del ponente matizando la naturaleza de la sociedad de responsabilidad limitada, o dando alguna recomendación al respecto. Este resultado ratifica la hipótesis antes señalada de que el Tribunal Supremo entra y analiza la causa específica del conflicto del recurso presentado, no la naturaleza de la sociedad de responsabilidad limitada (Cuadro 3).

\section{Cuadro 3}

DISCRIMINACIÓN DE CASOS ELEGIDOS: CRITERIOS

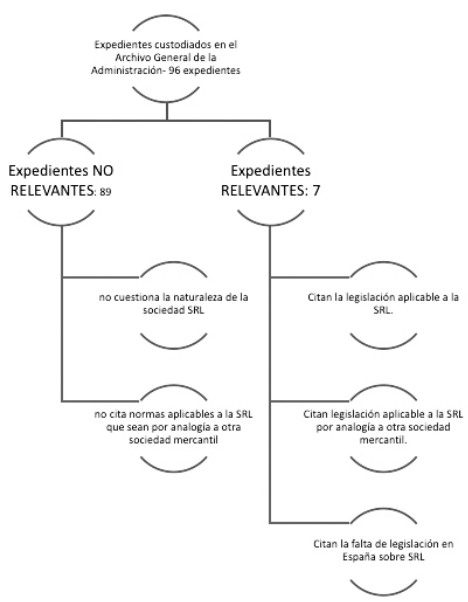

(Elaboración propia: base de datos propia de las "Sentencias del Tribunal Supremo sobre Sociedades de Responsabilidad Limitada - Archivo General de la Administración (Alcalá de Henares, Madrid)".

\section{ANÁLISIS DE CASOS}

A continuación, presento el análisis de todas las sentencias que muestran elementos discursivos en los que los miembros del Tribunal Supremo emiten 
una opinión particular sobre la sociedad de responsabilidad limitada. Incluso en el momento presente, según apuntan los expertos, los tribunales españoles son reticentes a reconocer que están sentando los fundamentos de una nueva le y, cuando cubren un hueco legal. De hecho, solo de forma excepcional se ha reconocido la existencia de dichas lagunas y la necesidad de llenarlas ${ }^{39}$. Se aborda el análisis de casos a través de secciones temáticas.

\section{La sociedad de responsabilidad limitada: una traducción sobreentendida}

En la base de datos dos casos ejemplifican la flexibilidad del sistema judicial español sobre qué era una sociedad de responsabilidad limitada, en el supuesto de entidades mercantiles extranjeras registradas en España. La sentencia de 5 de mayo de $1919^{40}$ se trata de un recurso de casación por infracción de la ley (cumplimiento de contrato de compraventa). La conocida sociedad anónima de capital británico Riotinto Limited Company, aparece clasificada como $1 \mathrm{i} \mathrm{m}$ i t a d a , por una traducción errada de limited que se refiera a la figura inglesa de sociedad anónima. Al tratarse de una sociedad extranjera, para operar en territorio nacional, tenía que inscribirse en el Registro Mercantil y allí aparecía como una limitada (debido a un error en la traducción). No existe ningún comentario sobre la naturaleza de la sociedad, porque no es motivo del pleito, y tampoco existe alusión al error en la clasificación de la figura legal, posiblemente porque el Registro Mercantil no había considerado nada irregular.

Años más tarde, en la Sentencia de 6 de mayo de $1940^{41}$ la sociedad que aparece como sociedad de responsabilidad limitada es una Gesellschaft mit beschränkter Haftung $(G m b H)$ alemana que acude al Tribunal Supremo español para hacer cumplir la decisión de un laudo arbitral de la cámara de comercio de Hamburgo. La documentación original, en alemán, se presenta traducida parte en francés y parte en español. No existe ningún problema de traducción de los términos y la equivalencia entre los tres tipos societarios es correcta, aunque en España aún no existía una ley sobre sociedades de responsabilidad limitada y las características de dicha la sociedad de responsabilidad limitada en Francia y Alemania eran diferentes $^{42}$. Entre los dos expedientes señalados en el presente epígrafe transcurren 21 años y también mucha información sobre las sociedades de responsabilidad limitada circulando por el país. E. Langle subraya la imposibilidad de una definición

\footnotetext{
${ }^{39}$ Ruiz Miguel, Alfonso; Laporta, Francisco J., cit. (n. 36), p. 272.

${ }^{40} N^{\circ} 42$, Tribunal Supremo, 6 mayo, publicada $1^{\circ}$ de octubre de 1920. Casación por infracción de ley. Cumplimiento del contrato de contraventa en Jurisprudencia Civil. Colección completa de las sentencias dictadas por el Tribunal Supremo (Madrid, Editorial Reus, 1923), LXVIII, pp. 245-249.

${ }^{41}$ Expediente del Archivo General de la Administración - Alcalá de Henares (Madrid) (en adelante AGA) Referenciado con el número de Expediente 41-3553 (en adelante Exp. 41_3553) y la cita completa: AGA Exp. 41-3553. Cumplimiento en España de fallo dictado en Hamburgo por Tribunal Arbitral en 29 de Julio de 1935. H. Meyery Compañia SL contra Félix Granell Fellis (Burriana-Castellón). Fallo emitido por el Presidente de la Sala de lo Civil del Tribunal Supremo D. Rafael Rubio 6 de mayo de 1940.

${ }^{42}$ Guinnane, Timothy; Rosenthal, Jean Laurent, Adapting the Law Fit the Facts: the GmbH, the SARL, and the Organization of Small Firms in Germany and France, 1892-1930, en Annual meetings of the Economic History Association (Vancouver- British Columbia 2012).
} 
unitaria, aunque también recalca la difusión universal de la figura, y la existencia de características comunes ${ }^{43}$.

\section{La flexibilidad del marco legal}

La primera sentencia de la doctrina del Tribunal Supremo sobre sociedad de responsabilidad limitada es la del 17 de noviembre de 1928. En la sentencia de 17 de noviembre de 1928 el escrito por parte del ponente del Tribunal Supremo, D. M. Crehuet ${ }^{44}$, pone de relieve el alcance del art. 122 al señalar que "no establece como únicas formas de compañia mercantil las que define seguidamente (sociedad colectiva, sociedad en comandita, sociedad anónima), y asi existen con plena eficacia jurídica la sociedad comanditaria por acciones y las de responsabilidad limitada, entre otras, no comprendidas en este precepto definidor" ${ }^{45}$.

La sentencia de 7 de agosto de $1956^{46}$ tiene interés por los detalles aportados durante el caso sobre el proceso particular de inscripción de la sociedad de responsabilidad limitada. Este dato muestra que en los años 1940 existía un control de la sociedad de responsabilidad limitada tal que no se aceptan sociedades con denominaciones peregrinas, como sí se observaban en los registros de los años 1930, sino que todas ellas deben estar claramente identificadas por su nombre y las siglas SL o SRL ${ }^{47}$. El aspecto relevante para el estudio es que la compañía implicada en el recurso de casación cuando se va a registrar opta por una figura denominada Sociedad Mercantil Regular Colectiva con capital limitado y razón social "Alejandro Allepuz e Hijos SL" ${ }^{48}$. Señala el recurso que dicho concepto era erróneo e incongruente y no fue aceptada en el Registro Mercantil por negativa del registrador, pero sí había sido recomendada por el notario que escribió las escrituras. Aquí aparece la eficiencia del doble control en el cumplimiento de la ley por parte de notarios y registradores. Recibida la negativa del registrador, se procedió a una rectificación de la forma legal y registrándola como una sociedad de responsabilidad limitada.

La sentencia del 13 de octubre de $1953^{49}$ destaca la responsabilidad limitada de los socios como la característica principal de la sociedad de responsabilidad limitada. Los comentarios del ponente del caso, J. Hinojosa Ferrer son previos a la aprobación de la Ley de Sociedades de Responsabilidad Limitada (1953). Pri-

${ }^{43}$ Langle, Emilio, Manual de derecho mercantil (Barcelona, 1950), pp. 628; 631-634.

${ }^{44} \mathrm{El}$ ponente del Tribunal Supremo, D. M. Crehuet, no puede ser considerado un experto en mercantil, al menos no en función de la obra publicada.

${ }^{45}$ S. 17-11-1928. N ${ }^{0}$ 34. Jurisprudencia Civil. Colección completa de las sentencias dictadas por el Tribunal Supremo ( $7^{\circ}$ de 1928, noviembre y diciembre), CLXXXVI, pp. 139-145.

${ }^{46}$ Expediente AGA Ref. [45-3427]. La sociedad Anónima Compañia Inmobiliaria de Inversiones, sociedad anónima, que utilizan el nombre de Zaragoza Urbana en autos seguidos con Don Alejandro Allepuz. Orcall por si y en representación de la Compañia Mercantil Alejandro Allepuz, SL.

${ }^{47}$ En el año 1953 se aprueba la creación de dicho registro. Decreto Registro General de sociedad de responsabilidad limitada, 22 de julio de 1953, en Colección Legislativa de España. 1953 (Madrid, 1954), XXIX, p. 346.

${ }^{48}$ AGA Expediente 45-3427, cit. (n. 46).

${ }^{49}$ AGA. Expediente 66-7179. Recurso de injusticia notoria interpuesto por la Compañia Mercantil Lópezy Casal, SL en los autos seguidos por D. Manuel Cañizo Gil sobre Resolución de contrato de arrendamiento. 
mero lamenta la parquedad de la ley y suscita otra cuestión clásica en el estudio de la sociedad de responsabilidad limitada en España: la potencial confusión con la sociedad colectiva. Pero el magistrado no ve ningún indicio a que se produzca dicha confusión ${ }^{50}$. De hecho, una vez aprobada la Ley de Sociedades de Responsabilidad Limitada, solo unos meses antes a la publicación de esta sentencia (18 de julio de 1953) la polémica quedó zanjada con el art. 2: "la sociedad habrá de girar bajo una denominación objetiva o razón social, a la que deberá añadirse, en todo caso, la indicación 'sociedad de responsabilidad limitada'.

\section{Las características de esta nueva sociedad}

En la sentencia 4 de febrero de 1929 el ponente del Tribunal Supremo, M. Avellón ${ }^{51}$, aporta una definición de sociedad de responsabilidad limitada más una serie de características. El ponente señala la personalidad jurídica propia de la sociedad de responsabilidad limitada, y diferente a la de sus socios, estableciendo un hecho diferencial fundamental con las sociedades en comandita y sociedad colectiva. A continuación, dota a la sociedad de responsabilidad limitada de cinco características $^{52}: 1$. Requisito esencial de que las participaciones que formen el capital social deban estar totalmente desembolsadas, y la necesidad de que haya una valoración de las que no sean aportaciones en metálico. 2. Las participaciones del capital social no podrán estar representadas por ninguna clase de títulos separados e independientes de la escritura de constitución. 3. Las participaciones de capital no pueden ser cedidas a terceros hasta transcurrido el plazo legal que en las mismas se determina. 4. En las sociedades de responsabilidad limitada puede un socio ejercitar la acción personal contra la sociedad para reclamar un crédito reconocido por ésta. La expresada acción no es pro-socio, sino otra distinta. 5. Si los pactos sociales no declaran incompatibilidad, el socio puede adquirir diferentes compromisos.

Esta caracterización del Tribunal Supremo generó debate. E. Taulet rebate varias de estas características. Primera, sobre la aportación y desembolso total del capital en el momento del inicio de sus operaciones señala el jurista que el Código de Comercio no exige tal condición a ninguna otra sociedad mercantil ${ }^{53}$. De hecho, la Real Orden de 28 de febrero de 1947 dictamina que las sociedades de capital no están obligadas al desembolso total del capital en el acto de consti-

\footnotetext{
${ }^{50}$ Ibíd.

${ }^{51}$ El ponente carece de obra mercantil publicada.

${ }^{52}$ Extracto de la sentencia: "es lo cierto que la naturaleza de esta sociedad de responsabilidad limitada impone que se determine bien lo que son derechos y deberes de los socios y de la sociedad por provisiones, ventas, depósitos, etc., porque en esta clase de sociedades es requisito esencial que al constituirse queden totalmente cubiertas las participaciones en que se haya dividido el capital social, y aportadas las mismas en la forma estipulada, y es igualmente requisito preciso el que se haga la valoración de las que consisten en bienes que no sean en metálico, y, por último, que las participaciones del capital social no podrán estar representadas por ninguna clase de títulos separados o independientes de la escritura de constitución, no pudiendo ser cedidas a personas extrañas a la sociedad hasta transcurrido el plazo legal que en las mismas se determine". $N^{\circ} 94$, Tribunal Supremo, 6 febrero 1929 mayo. Casación por infracción de ley. Sociedad Limitada en Jurisprudencia Civil. Colección completa de las sentencias dictadas por el Tribunal Supremo (Madrid, 1930), CLXXXVII, p. 510.

${ }^{53}$ TAulet, Enrique, cit. (n. 35), p. 17.
} 
tución y E. Taulet señala que en su práctica notarial sí había admitido sociedades de responsabilidad limitada con participaciones sueltas ${ }^{54}$. De hecho, va más allá y sugiere que la sociedad de responsabilidad limitada no emitía acciones para evitar ese gasto, que sí es obligatorio en las sociedades anónimas ${ }^{55}$. Apostilla finalmente que el Reglamento del Registro Mercantil solo pide a la sociedad de responsabilidad limitada que conste esta condición y no dice nada del capital dividido, o no, en acciones. E. Taulet considera lo anterior "un olvido imperdonable" que tendría que haberse resuelto, y no había sido así. F. Navarro, por el contrario, valoraba positivamente esta sentencia del Tribunal Supremo y apuntaba que se inspiraba en el proyecto del código de comercio de 1926 que tampoco permitía que la sociedad de responsabilidad limitada estuviera dividida en participaciones de capital social. Además, F. Navarro, señala a J. Garrigues como uno de los juristas que para diferenciar entre sociedad anónima y sociedad de responsabilidad limitada apela al capital dividido en acciones. F. Navarro también señala que la práctica notarial "de manera unánime" había adoptado el tipo personalista para la sociedad de responsabilidad limitada en la que (si bien pueden existir excepciones, dado que la ley lo permite) cada socio en escritura fundacional participa en el capital con una cuota única ${ }^{56}$. Por último, E. Taulet cuestiona que el Tribunal Supremo considere que las participaciones no pueden ser cedidas hasta que no transcurra el plazo legal. Apelando al Reglamento del Registro Mercantil afirma que éste guarda silencio al respecto, y por lo tanto nada objetivo avalaba el criterio del Tribunal Supremo.

\section{La sociedad de responsabilidad limitada y su cercanía a la sociedad colectiva}

La Sentencia de 5 julio de 1940 declara aplicable a las sociedades de responsabilidad limitada el art. 125 del Código de Comercio referido a los elementos constitutivos de la escritura social de la sociedad colectiva. En consecuencia, deberá aparecer en toda escritura de sociedad de responsabilidad limitada "el nombre y apellidos y domicilio de los socios, la razón social de Sociedad [...]; el capital que cada socio aporta en dinero efectivo, créditos o efectos con expresión del valor que se da a éstos; domicilio de la Sociedad, con expresión del lugar en que está establecida [...]; clase de comercio u operaciones a que se dedica y la fecha de su constitución". En caso de ausencia de información sobre los gestores, todos los socios concurren en la dirección, y el ponente informa de que se les aplicaría el art. 129 del Código de Comercio sobre la potestad de todos los socios de la sociedad colectiva. En cuanto a la duración, de no figurar ningún pacto concreto, el plazo sería indefinido y se le aplicarían los motivos de disolución en una sociedad colectiva, o una sociedad en comandita, que tuviera la característica de duración indefinida; es decir, si alguno de los socios exigiere su disolución, los demás no podrían oponerse sino por causa de mala fe en el que lo proponga (art. 124 Código de Comercio). El ponente del Tribunal Supremo también apunta que, en los supuestos concretos de las reglas para la formación

${ }^{54}$ Ibíd, p.18.

${ }^{55}$ Ibíd.

${ }^{56}$ Navarro, Fausto, La configuración de la sociedad limitada a través de la práctica notarial, en Revista de Derecho Privado, 26 (1942), p. 30. 
de los balances, reparto de utilidades, constitución de reservas, u otras directrices para la liquidación y división del haber social son los pactos particulares los que deben hablar. En ningún momento apela a la regulación de la sociedad anónima.

La Dirección General del Registro y el Notariado remitió a esta sentencia en la Resolución emitida el 30 de marzo de 1951 para resolver un caso de destitución del gerente y la rescisión parcial de la sociedad. Y consideraba procedente aplicar a tales sociedades de responsabilidad limitada las normas que afectaban a la sociedad colectiva, en lo referente a las relaciones internas entre los socios y acudiendo a la sentencia de 5 de julio de 1940.

Otra sentencia relevante fue la del 5 de julio de 1941, comentada en la Revista General de Legislación y Jurisprudencia. El ponente del Supremo, J. Castán ${ }^{57}$ aporta aclaraciones relevantes sobre la aplicación de artículos del Código de Comercio que se refieren a la sociedad colectiva y la sociedad en comandita y que también -según el ponente- resultaban aplicables a las sociedades de responsabilidad limitada. J. Castán señala que la sociedad de responsabilidad limitada es un tipo de sociedad híbrido entre sociedades de personas y las compañías de capitales “y así, mientras en el sistema germánico predomina la similitud en la Compañía Anónima, en el régimen de las legislaciones latinas es mayor, por el contrario, el parecido con la sociedad colectiva y comanditaria, viniendo a ser la responsabilidad limitada una sociedad de tipo personalista en la que se injerta el principio de limitación hasta cierta suma de la responsabilidad de los socios". Y para no dejar resquicio de duda sobre la falta de cercanía entre la sociedad de responsabilidad limitada y la sociedad anónima en España, J. Castán recalca que la evidencia definitiva es que no tenía un órgano de dirección similar a la asamblea general de la sociedad anónima. La analogía entre un modelo germánico y uno francés también sería utilizada por la Dirección General del Registro y el Notariado. Años más tarde, J.M. Boix vuelve a insistir en la naturaleza mixta de la sociedad de responsabilidad limitada y señalará que la "técnica jurídica moderna no requiere de un acoplamiento necesario con respecto la distinción binaria: sociedad capitalista vs. Personalista" 58 . Otro autor, E. Langle, apuntaba que dicho carácter híbrido de la sociedad limitada había sido reconocido universalmente ${ }^{59}$.

La Revista General de Legislación y Jurisprudencia explicitó su acuerdo con la postura del Tribunal Supremo. La realidad económica mostraba que las sociedades de responsabilidad limitada se constituían ordinariamente por personas que deseaban encontrarse en situaciones análogas a la de los miembros de una colectiva, pero sin tener el inconveniente, o riesgo, de la responsabilidad limitada ${ }^{60}$. Según A.

\footnotetext{
${ }^{57}$ Una breve biografía de J. Castán, así como de los principales juristas españoles se encuentra en Diccionario de catedráticos españoles de derecho (1847-1943) (Madrid, Universidad Carlos III de Madrid. Instituto Figuerola de Historia y Ciencias Sociales, 2011) [http://portal.uc3m. es/portal/page/portal/instituto_figuerola/programas/phu/diccionariodecatedraticos]

${ }^{58}$ Boix Raspall, José María, Ley sobre régimen juridico de las Sociedades de Responsabilidad Limitada, en Revista Jurídica de Cataluña 70 (1953), p. 516.

${ }^{59}$ Langle, Emilio, Manual de derecho mercantil (Barcelona, 1950), pp. 628; 631-634.

${ }^{60}$ Vicente-Gella, Agustín, Aplicación a las compañias de responsabilidad limitada. Sentencia 3 de Julio de 1941, en Revista General de Legislación y Jurisprudencia, 86 (1941), p. 626.
} 
Vicente-Gella, las sociedades de responsabilidad limitada en España tienen las siguientes características "por lo general los socios de las compañías limitadas (1) intervienen todos en la administración de la empresa; (2) cada uno de sus componentes toma en cuenta la personalidad de los demás; por regla general (3) las participaciones sociales se consideran transmisibles precisamente porque un determinado titular no tiene inconveniente en formar parte de la compañía cuando sus demás socios son sujetos que conoce y en cuya actuación tiene confianza, pero no estaría dispuesto a entrar en cualquier sociedad de desconocidos aun cuando advirtiera la posibilidad de beneficios superiores". A. Vicente-Gella, deja caer una advertencia sobre cómo tendría que ser la futura ley de la sociedad de responsabilidad limitada, justificando la necesidad de respetar la proximidad entre sociedad colectiva y sociedad de responsabilidad limitada, por la analogía entre ambas figuras.

La sentencia del 5 Julio de 1941, fue objeto además de comentario en la Revista Derecho Privado por A. Polo ${ }^{61}$. El jurista asentía en lo evidente que era en España el carácter personalista de la sociedad de responsabilidad limitada, pero manifestaba que eso no era un signo inequívoco de que la futura ley positiva fuera en esa dirección ${ }^{62}$. A. Polo advertía que encasillar a la sociedad de responsabilidad limitada en un modelo muy próximo a la sociedad colectiva podía suponer una eliminación de los rasgos que la habían hecho tan exitosa ${ }^{63}$. Otro aspecto relevante que introduce es en cuanto a la tipificación de la sociedad de responsabilidad limitada. J. Castán las agrupaba en dos grandes grupos: el germano, de similitud con la sociedad anónima, y el modelo latino. Apunta J. Castán que la sociedad de responsabilidad limitada guardaba un mayor parecido con la sociedad colectiva y la sociedad en comandita. A. Polo por el contrario pone como países seguidores del modelo de sociedad de responsabilidad limitada a Alemania (1892), Austria (1906), Checoslovaquia (1920) Polonia (1919 y 1923) Bulgaria (1924) y Hungría (1924), entre otros. La matización reside en que, en los países de carácter latino, como Portugal (1901), Francia (1925) e Italia (1925, proyecto de código de comercio), tampoco -señala A. Polo- existe tanta cercanía con la sociedad colectiva, o la sociedad en comandita. En el caso de Francia, la ley de la sociedad

\footnotetext{
${ }^{61}$ Autor que contaba con un gran bagaje investigador sobre la sociedad de responsabilidad limitada. Cabe añadir la siguiente información: Polo es considerado uno de los renovadores del derecho mercantil, y miembro de la Moderna Escuela Española de Derecho Mercantil fundada por Garrigues. Accede a su cátedra en 1935 en una plaza disputada por otros candidatos. Entre los miembros de la comisión evaluadora estarán J. Castán, que apoyó a otro candidato, y J. Garrigués que apoyó a A. Polo. La relación profesional, e incluso de amistad personal, entre Polo y Garrigues está documentada y acreditada por su paso por el Instituto de Estudios Fiscales y la Revista de Derecho Mercantil. El proyecto de redacción de la Ley de Sociedades Anónimas ya se había iniciado a mediados de la década de los 1940, pues en 1947 el Instituto de Estudios Fiscales, a petición del Ministerio de Justicia, publicó un anteproyecto de sociedad anónima. El Instituto de Estudios Fiscales era un instituto de investigación, pero también un think tank para el régimen de Franco. Garrigues, Joaquín; González, Jerónimo; de la PlazA, Manuel; Uría, Rodrigo; Rodríguez Gimeno, Antonio; Palao, Juan E.; Sáinz de Bujanda, Francisco, Reforma de la Sociedad Anónima (Madrid, Instituto de Estudios Políticos, 1947).

${ }^{62}$ Polo, Antonio, Sociedades, en Revista de Derecho Privado, 302 (1942), pp. 245-249.

${ }^{63}$ Ibíd, p. 249.
} 
de responsabilidad limitada se derivó de la necesidad de dar amparo legal a las $\mathrm{GmbH}$ que surgieron en las zonas de Alsacia y Lorena, que no seguían precisamente un criterio personalista ${ }^{64}$. En el caso de Italia, el proyecto del código civil de 1941 era más cercano a la sociedad anónima que a las formas personalistas. La explicación de este cambio de orientación frente al proyecto anterior era el de reservar la figura de la sociedad anónima para las grandes empresas, y para que la sociedad de responsabilidad limitada cumpliese la función hasta entonces cubierta por las sociedades anónimas para empresas de menor capital. E. Taulet también se hace eco del comentario de A. Polo ${ }^{65}$. En las mismas fechas, F. Navarro señala con rotundidad que la sociedad de responsabilidad limitada es un tipo de sociedad colectiva ${ }^{66}$.

La sentencia 7 de octubre $1949^{67}$ muestra un recurso de casación por infracción de la ley en el que la parte demandante apela a los artículos del estado de quiebra de una sociedad colectiva para que sean aplicados a una sociedad de responsabilidad limitada (al solicitar el beneficio de pobreza) ${ }^{68}$. En la sentencia de 18 de febrero de $1948^{69}$ el ponente C. Valledor considera oportuno añadir a su intervención una serie de consideraciones sobre la naturaleza de la sociedad de responsabilidad limitada. De todos los casos analizados de la base de datos confeccionada con la información del Archivo General de la Administración (Alcalá de Henares, Madrid) es el único cuyas teorías aparecen bajo el epígrafe de Doctrinal. El jurista encuadra la sociedad de responsabilidad limitada de sociedad personalista, cercana o asimilable a la sociedad colectiva. Aun así, hay determinados preceptos que atendiendo a cada caso particular, no son aplicables. En esta sociedad de responsabilidad limitada, en concreto, no son aplicables los artículos 221 y 223 del Código de Comercio sobre cese de entidad con duración limitada porque es de duración ilimitada. Y entra en juego preferente (según el art. 221) el pacto particular de escritura por la que los socios deciden terminar con la sociedad. Y solo de forma supletoria será aplicado el art. 224 del Código de Comercio.

En la sentencia 19 de junio de $1952^{70}$ es relevante la consideración del ponente,

\footnotetext{
${ }^{64}$ Para una rigurosa y ágil revision de la GmbH: Guinnane, Timothy, W., Creating a new legal form for enterprise: the German GmbH, 1892-1914. Presentación en el Centerfor Finantial Studies- Goethe Universität, 2015.[https://www.ifk-cfs.de/media-lounge/news/detail/article/creating-a-newenterprise-form-the-gmbh.html]

${ }^{65}$ TAulet, cit. (n. 35), pp. 19-20.

${ }^{66}$ Navarro, Fausto, cit. (n. 56), p. 26.

${ }^{67}$ AGA. Exp. 41-3386. Recurso de casación por infracción de ley. Los Hispanos Textil SL en autor seguidos con Moravia SA.

${ }^{68} \mathrm{El}$ ponente del Tribunal Supremo es J. M. Rodríguez de los Ríos y entre los siete miembros del Tribunal Supremo están dos magistrados que ya habían sentado doctrina sobre la sociedad de responsabilidad limitada: J. Castán y C. Valledor.

${ }^{69} N^{o} 58$, Tribunal Supremo, 18 febrero 1948. Recurso de casación por infracción de ley. Sociedades de responsabilidad limitada: su asimilación al régimen de las Sociedades personalistas en Jurisprudencia Civil. Colección completa de las sentencias dictadas por el Tribunal Supremo (Madrid, 1950), XXI, pp. 531-534.

${ }^{70} N^{o} 233$, Tribunal Supremo, 19 junio de 1952. Casación por infracción de ley. Principios Generales en Jurisprudencia Civil. Colección completa de las sentencias dictadas por el Tribunal Supremo (Madrid, Editorial Reus, 1953), XXVI, pp. 321-333.
} 
de nuevo C. Valledor, sobre la cercanía de la sociedad de responsabilidad limitada a la sociedad colectiva al dictar la aplicabilidad del artículo sobre disolución o rescisión parcial de sociedad colectiva o/y sociedad en comandita a la sociedad de responsabilidad limitada, en virtud del art. 218 del Código de Comercio, al repetir el mismo criterio, y la consideró como entidad de tipo personalista, con un régimen interno similar a la sociedad colectiva, aunque con la nota peculiar frente a terceros de limitación de responsabilidad de los socios integrantes.

El último comentario corresponde a una sentencia del 13 de octubre de $1953^{71}$, una vez ya se había aprobado y puesto en vigor la nueva ley de sociedad de responsabilidad limitada, porque el ponente -J. Hinojosa Ferrer-vuelve a la sentencia del 5 de julio de 1941 para incidir en que la sociedad de responsabilidad limitada tenía "más claro anclaje y adaptación” a las normas de la sociedad colectiva. La ley de 1953 remitía en reiteradas veces a la Ley de Sociedades Anónimas de 1951, para cubrir las potenciales eventualidades que el mismo texto no contemplaba $^{72}$. Y aún así, con ley aprobada, los miembros del Supremo seguían fieles al precedente que habían creado.

\section{Poniendo en práctica lo aprendido: del precedente a la ley}

En el preámbulo de la Ley de Sociedades Anónimas (1951) se declara la intención del legislador de respetar y reconocer la labor legislativa efectuada por el Tribunal Supremo y la Dirección General del Registro y el Notariado, pero no por ello los redactores de la ley, dirigidos por J. Garrigues, dejaron de imprimir su convicción de que la sociedad de responsabilidad limitada era el receptáculo de las sociedades anónimas que ya no tenían cabida en la nueva sociedad anónima. ¿Se fundieron las dos voluntades? En la Revista Catalana de Jurisprudencia ( $\mathrm{n}^{\mathrm{o}} 1$ y 6 , 1953) aparecen opiniones que subrayan que la nueva ley respetaba la tradición $n^{73}$; y otros que dejaban patente la clara cercanía con la sociedad anónima ${ }^{74}$; e incluso algunos autores subrayaban su valor intermedio ${ }^{75}$. Algunos juristas han analiza-

${ }^{71}$ AGA. Exp. 66-7179. Recurso de injusticia notoria interpuesto por Lópezy Casal, SL en los autos seguidos por D. Manuel Cañizo Gil sobre Resolución de contrato de arrendamiento.

${ }^{72}$ Pelletier, Alejandro, Interpretación práctica de la ley de sociedades limitadas (Madrid, 1956).

73 "Por ello la nueva ley no ha hecho sino recibir en su mayoría la regulación anterior, así en lo referente las formalidades de la constitución (compárese el art. 5 de la Ley con el art. 119 del Código de Comercio), como en lo que hace relación con suscripción y desembolso del capital (art. 3 en relación con la sentencia del 4 de febrero de 1929). SALVAdOR GULLÓN, Pablo; SALVAdOR Gullón, Hilario, Fundación de la Sociedad Limitada, en Revista Jurídica de Cataluña, 70 (1953), p. 530.

${ }^{74}$ Señala el autor a continuación citado: "Sin embargo, esta equidistancia perseguida por el legislador, con todo su buen deseo, no aparece en la ley. No es una sociedad colectiva con limitación de responsabilidad, ni una anónima. Pero por sus líneas fundamentales resulta indudablemente un anónima de tipo mitigado o reducido en la complicada vida de esta forma asociativa”. Gay de Montellá, Rafael, Un juicio sobre el proyecto de Ley de Sociedades de Responsabilidad Limitada, en Revista Jurídica de Cataluña, 70 (1953), p. 504. Señala el autor a continuación citado: "La Ley sobre régimen jurídico de las sociedades de responsabilidad limitada es, como la de las anónimas, de fecha 17 de julio, con sólo dos años de diferencia (1951-1953)". Boix Raspalt, José María, cit. (n. 59) p. 512.

${ }^{75}$ Señala el autor a continuación citado: "Las sociedades de responsabilidad limitada son intermediarias entre unas y otras; participan de los respectivos caracteres de aquellas, pero con 
do la importancia que tenía la forma legal de la sociedad mercantil; de cómo el empresario al decantarse por una u otra sociedad también estaba modelando las características fundamentales de la empresa: la responsabilidad de los socios, quién tendría acceso a la gestión, cómo se tomarían las decisiones ${ }^{76}$. En el proceso final de la elaboración de ley de sociedades de responsabilidad limitada un aspecto que destacó sobre los demás, y fue el tamaño de la firma. Para el legislador estaba claro que las leyes de la sociedad anónima y la sociedad de responsabilidad limitada eran sobre todo colectores de grandes y pequeñas y medianas empresas -respectivamente-. Esta forma de analizar la situación fue un elemento limitador de la legislación generada ${ }^{77}$.

En primer lugar, el articulado de la ley de 1953 cerraba una polémica clásica a propósito del nombre de la sociedad de responsabilidad limitada: tendría que ser una razón social y siempre seguida de la expresión sociedad de responsabilidad limitada (art. 2). La sentencia del Tribunal Supremo de 4 de febrero de 1929 ya determinaba una serie de elementos obligatorios en la escritura social y el art. 7 los ampliaba con el objetivo de ofrecer una mayor publicidad de la sociedad.

Respecto al criterio del Tribunal Supremo de que el capital ha de estar desembolsado (art. 3), y siguiendo una sintonía con las legislaciones europeas, la ley marca un mínimo de 500.000 pesetas. (Cabe recordar que para sociedades con más de 5 millones la única opción posible era la sociedad anónima). Siguiendo con el capital, establece que se consideraba posible la transmisión inter vivos y mortis, alegando que el intuitus personae no era tan fuerte en las sociedades de responsabilidad limitada como para negar a su nombre el principio general de negociabilidad de los bienes, pero por sus características se establecía un derecho de tanteo a favor de los otros socios y, supletoriamente, a favor de la sociedad. La subsidiaridad del régimen de las anónimas para tratar temas relacionados con la transmisibilidad se explicita. Por último, el capital debería de estar expresado en unidades monetarias nacionales (art. 8 y art. 9).

En cuanto a las causas de disolución, remite a la Ley de Sociedades Anónimas porque es más completa (art. 30) y también explicita la validez del art. 221 de Código de Comercio en los supuestos no contemplados en el art. 30 de la misma (art. 31).

Otro punto de interés es la administración de la sociedad, que en el caso de superar los 15 socios estaría obligada a formar una Junta General. De nuevo aquí la Ley de Sociedades de Responsabilidad Limitada no está desarrollada y remite directamente a la Ley de Sociedades Anónimas (art. 14). Este artículo es clave para entender la proximidad que el legislador establece entre los dos tipos de sociedades. También en lo referente a las cuentas anuales seguirían lo dispuesto en la Ley de Sociedades Anónimas (capítulo 7 de la Ley de Sociedades Anónimas) (art. 26).

$\mathrm{Ni}$ el proceso de elaboración de la ley de la sociedad de responsabilidad

personalidad independiente. Son el lazo de unión entre unas y otras, llenando el vació (526) entre ellas". PIÑoL, Josep, Régimen jurídico de las sociedades de responsabilidad limitada, en Revista Jurídica de Cataluña, 70 (1953), pp. 525.

${ }^{76}$ Guinnane, Timothy W.; Martínez-Rodríguez, Susana, cit. (n. 9).

${ }^{77}$ Boix Raspall, José María, cit. (n. 59). 
limitada, ni el debate generado a su alrededor tuvo comparación con el de la sociedad anónima, si bien los padres intelectuales de ambas fueron los mismos ${ }^{78}$. Ninguno de los actores implicados era consciente de la repercusión que la sociedad de responsabilidad limitada tendría en la modernización de la economía española. Los intelectuales de la época, y en concreto el grupo de J. Garrigues, estaba pendiente del desarrollo de las grandes empresas en las que, sin duda, la sociedad anónima había jugado un papel determinante. Como décadas más tarde ratificaría A. Chandler, fueron las modernas corporaciones las que guiaron la modernización de la economía ${ }^{79}$. Desde comienzos del siglo XX se publicaba de forma anual un volumen de referencia en España con todas las sociedades financieras y mercantiles que con la forma de sociedad anónima eran la avanzadilla del desarrollo económico del país ${ }^{80}$. Existía una convicción extendida de que el peso económico del país residía en la pujanza de las grandes sociedades anónimas y que éstas eran a las que había que prestar mayor atención. La gran empresa, pública y privada, recibió un trato de favor en los años 1950 y 1960 por parte del régimen político del dictador $\mathrm{Franco}^{81}$, por lo que es coherente que el legislador extendiera ese trato especial. Sin embargo, la red de negocios pequeños, que dirigían el pulso comercial y empresarial diario estaba protagonizado por la novedosa sociedad de responsabilidad limitada. Su popularidad obedeció a que permitió a los empresarios acceder a ventajas organizativas anteriormente reservadas a las sociedades anónimas, pero sin asumir su costosa administración. En la actualidad más del 98\% de todas las nuevas sociedades mercantiles creadas en España continúan adoptando la figura de sociedad de responsabilidad limitada ${ }^{82}$.

\section{CONSIDERACIONES FINALES}

La sociedad de responsabilidad limitada es una de las innovaciones más importantes en materia de sociedades del siglo XX, y su implementación ha gozado además de gran éxito. En los países europeos, con derecho continental, la ley escrita recogía todos los rasgos esenciales de dicha sociedad y las normas por las que se regía. La ley actuaba de hoja de ruta de la sociedad de responsabilidad

\footnotetext{
${ }^{78}$ Martínez-Rodríguez, Susana. History of Corporations in Spain in the 20 $0^{\text {th }}$ Century: Towards Europe, en WeLls, Harwell, Research Handbook on the History of Corporate and Company Law (Chelthenham, 2018) pp. 298-322.

${ }^{79}$ CHAndLER, Alfred. The visible hand. The managerial Revolution in American Business (Cambridge, Harvard Business Press, 1977).

${ }^{80}$ Riu y Periquet, Daniel, Anuario Financiero y de las Sociedades Anónimas de España (Madrid, Mauricio Legrenge). El primer volumen es de 1918 y cesó la publicación en 1980. Información recuperada de: [http://datos.bne.es/edicion/bise0000030488.html].

${ }^{81}$ CARRERAS, Albert. La gran empresa durante el primer franquismo en SÁnCHEZ, Glicerio y TASCón, Julio (coords.), Los empresarios de Franco: política y economía en España, 1936-1957 (Alicante, 2003), pp. 47-66.

${ }^{82}$ La persona lectora interesada puede consultar la información estadística del INE (Instituto Nacional de Estadística) referida a las sociedades mercantiles en España: [https://www.ine.es/ dyngs/INEbase/es/operacion.htm?c=Estadistica_C\&cid $=1254736177026 \&$ menu=resultado s\&secc $=1254736195506 \&$ idp $=1254735576550 \#$ ! tabs-1254736195507].
} 
limitada, y en caso de no ser seguida, correspondía a las cortes efectuar su correcta interpretación. La sociedad de responsabilidad limitada en España difiere de esta norma, porque proliferó sin una ley propia, y este fue un hecho excepcional. En dicho marco, el Tribunal Supremo construyó un armazón teórico para la sociedad de responsabilidad limitada utilizando como referencia las normas del Código de Comercio para la sociedad colectiva, que actuaron como reglas supletorias. Pero cuando en 1953 se aprobó una ley para este tipo de sociedades, ésta ignoró el precedente creado por la máxima autoridad jurídica. En el presente artículo se ha realizado una meticulosa investigación basada en fuentes archivísticas y en la interpretación y lectura de los juristas de la época para buscar las razones que llevaron a esta situación de rechazo de una fuente de autoridad como lo era el Tribunal Supremo.

A través de la elaboración de una base de datos de sentencias se ha probado que el Tribunal Supremo creó, en efecto, un precedente sobre la sociedad de responsabilidad limitada, pero se trató de un precedente débil, y esta afirmación se sostiene por dos hechos demostrados en la investigación: i) la decreciente valorización de la jurisprudencia como fuente del derecho entre los juristas, lo que se manifestó también en que algunas de las sentencias del Tribunal Supremo fueran directamente cuestionadas por expertos en revistas especializadas; ii) la evidencia de que en muy pocas sentencias del Tribunal Supremo los ponentes elaboraron doctrina sobre la figura en sí de la sociedad de responsabilidad limitada (sus características, o normas de funcionamiento). El Tribunal Supremo articuló un discurso coherente en el que se subrayaba la proximidad de sociedad de responsabilidad limitada a la sociedad colectiva, y por tanto se le aplicaban las normas de la última. Fue, además, coherente con sus dictámenes, porque en sus sentencias repitió el argumento de proximidad entre sociedad colectiva y sociedad de responsabilidad limitada, apelando a los artículos correspondientes del Código de Comercio. Por otro lado, los ponentes en sus sentencias apenas realizaron aportaciones doctrinales con las que crear un corpus legislativo nuevo. Este comportamiento obedece a un esencial respeto a la división de poderes, y estricto cumplimiento de su labor de interpretación de la ley escrita.

Otro elemento que explica que la ley de 1953 no tenga en consideración la experiencia previa del Tribunal Supremo se debe a que el grupo encargado de redactar la ley de sociedades de responsabilidad limitada la concebía como una ley accesoria de la sociedad anónima, al amparo de la cual acoger a aquellas sociedades anónimas menores de cinco millones de pesetas de capital que ya no tenían cabida dentro de la nueva ley de sociedad anónima. En esta historia también hay un elemento novelesco: una rivalidad entre escuelas y maestros en la que una tendencia se impone sobre la otra, al ser el redactor de la Ley de Sociedades de Responsabilidad Limitada el grupo liderado por J. Garrigues, redactor también de la Ley de Sociedades Anónimas (1951).

La particular historia de la Ley de Responsabilidad Limitada en España, es, como se ha mostrado, la historia de un precedente fallido. Es un caso de interés para la literatura jurídica internacional porque ofrece elementos de reflexión que trascienden el estudio particular, y permiten analizar con detalle cómo se produce la incorporación de una nueva figura legal a un menú societario ya existente, y 
qué papel juegan las instituciones, hasta el punto de que un impulso exógeno truncó su trayectoria.

BiBLiografíA

Fuentes archivística citadas

AGA: Archivo General de la Administración. Fondo de Justicia. Tribunal Supremo. AGA. Ref. 41-3386. Recurso de casación por infracción de ley. Los Hispanos Textil SL en autor seguidos con Moravia SA.

AGA Ref. 41-3553. Cumplimiento en España de fallo dictado en Hamburgo por Tribunal Arbitral en 29 de Julio de 1935. H. Meyer y Compañía SL contra Félix Granell Fellis (Burriana-Castellón). Fallo emitido por el Presidente de la Sala de lo Civil del Tribunal Supremo D. Rafael Rubio 6 de mayo de 1940.

AGA Ref. 45-3427. Recurso de injusticia notoria. La Sociedad Anónima Compañía inmobiliaria de inversiones SA en autos seguidos con D. Alejandro Allepuz Orcall.

AGA. Ref. 66-7179. Recurso de injusticia notoria interpuesto por López y Casal, SL" en los autos seguidos por D. Manuel Cañizo Gil sobre Resolución de contrato de arrendamiento.

\section{Literatura}

Benito, Lorenzo, Manual de derecho mercantil de España y de las principales naciones de Europa y América (Valencia, [1904] 1924), 3 vols.

Blanco Constans, Francisco, Estudios elementales de derecho mercantil segín la filosofía, la bistoria y la legislación vigente en España y en las principales naciones de Europa y América (Madrid, 1885) (Revista General de Legislación y Jurisprudencia, Madrid-Granada, 1897) (Madrid, 1901-1902, 2 tomos.

Borx Raspall, José María, Ley sobre régimen jurídico de las Sociedades de Responsabilidad Limitada, en Revista Jurídica de Cataluña, 70 (1953), pp. 506-524.

Carreras, Albert. La gran empresa durante el primer franquismo, en SÁnCHEZ, Glicerio y TASCÓN, Julio (coords.), Los empresarios de Franco: política y economía en España, 19361957 (Alicante, 2003), pp. 47-66.

Castellar, Enrique, Sociedades Mercantiles a Responsabilidad Limitada, en Revista Jurídica de Cataluña, 1 (1895), pp. 436-441.

CHAnder, Alfred. The visible hand. The managerial Revolution in American Business (Cambridge, 1977).

Código de Comercio de 1829 decretado y sancionado el 30 de mayo de 1829 [http:// fama2. us.es/fde/ocr/2006/codigoDeComercio1829.pdf]

Código de Comercio promulgado en 22 de agosto de 1885 y concordado con el de 30 de mayo de 1829, por D José María Ros Biosca (Valencia, 1886).

Decreto Registro General de sociedad de responsabilidad limitada, 22 de julio de 1953. Colección Legislativa de España. 1953 (Madrid, 1954), XXIX, p. 346.

Diccionario bibliográfico Electrónico de la Real Academia de Historia. Real Academia de la Historia [http://dbe.rah.es/]

Diccionario de catedráticos españoles de derecho (1847-1943) (Madrid, Universidad Carlos III de Madrid. Instituto Figuerola de Historia y Ciencias Sociales 2011),

[http://portal.uc3m.es/portal/page/portal/instituto_figuerola/programas/phu/ diccionariodecatedraticos]

Dirección General del Registro y el Notariado, Anuarios de la Dirección General del Registro y del Notariado (Madrid, 1920-1953). 
Eizaga Gondra, Martín, Problemas actuales de la sociedad de responsabilidad limitada, en Revista de Derecho Mercantil, 2/4 (1946), pp. 83-105.

Estasén, Pere, Instituciones de derecho mercantil (Madrid, 1890-1907).

- Tratado de las sociedades mercantiles y demás entidades de carácter comercial según el derecho español (Madrid, 1906).

Fon, Vincy; PARISI, Francesco, Juditial precedents in civil law, en Internatinal Review of Law and Economics, 26/4 (2006), pp. 519-535.

Garrigues, Joaquín, Curso de derecho mercantil. (Madrid, 1936-1940).

Garrigues, Joaquín; González, Jerónimo; de la Plaza, Manuel; Uría, Rodrigo; Antonio Rodríguez Gimeno, Antonio; Palao, Juan E.; Sáinz de Bujanda, Francisco, Reforma de la Sociedad Anónima (Madrid, 1947).

Garvey Algero, Mary, The Sources of Law and the Value of Precedents: A Comparative and Empirical Study of a Civil Law State in a Common Law Nation, en Lousiana Law Review, 65/2 (2005), pp. 775-822.

Gay de Montella, Rafael, El Código de Comercio Español (Barcelona, 1936).

—Las Sociedades de Responsabilidad Limitada (Barcelona, [1948] 1954).

—Un juicio sobre el proyecto de Ley de Sociedades de Responsabilidad Limitada, en Revista Jurídica de Cataluña, 70 (1953), pp. 503-505.

Guinnane, Timothy W. Creating a new legal form for enterprise: the German GmbH, 1892 1914. Presentación en el Center for Financial Studies-Goethe Universität, 2015. [https://www.ifk-cfs.de/media-lounge/news/detail/article/creating-a-newenterprise-form-the-gmbh.html]

Guinnane, Timothy W.; Harris, Ron y Lamoreaux, Naomi, Contractual Freedom and Corporate Governance in Britain in the Late Nineteenth and Early Twentieth Centuries, en Business History Review, 91/2 (2017), pp. 227-277.

Guinnane, Timothy W.; Martínez-Rodríguez, Susana, Choice of the Enterprise form: Spain 1886-1936, en Journal of Law, Economics and Organization, 34/1 (2018), pp. 1-26.

-Flexibility in the Spanish Company Law, 1886-1936, en Revista de Historia Industrial, 56 (2014), pp. 81-113.

—Instructions not included: Spain's Sociedad de Responsabilidad Limitada, 1919-1936, en European Review of Economic History, 22 (2018), pp. 462-482.

Guinnane, Timothy W.; R. Harris, Ron N. R.; Lamoreaux, Naomi; Rosenthal, Jean Laurent, Putting the Corporation in its Place, en Enterprise and Society, 8/3 (2007), pp. 687-729.

Guinnane, Timothy; Rosenthal, Jean Laurent, Adapting the Law Fit the Facts: the $\mathrm{GmbH}$, the SARL, and the Organization of Small Firms in Germany and France, 18921930, en Annual meetings of the Economic History Association (Vancouver-British Columbia, 2012).

Instituto Nacional de Estadística, Censo de Sociedades y empresas, 1951 (Madrid, 1951).

Iturralde, Victoria, Precedente Judicial, en Eunomia. Revista en la Cultura de la Legalidad, 4 (2003), pp. 194-201.

LAsso, Juan Francisco, Crónica de la codificación española: organización judicial (Madrid, 1999).

Martín de Eixala, Ramón, Instituciones de derecho mercantil de España ( $5^{\mathrm{a}}$ ed. puesta al día por M. Duran y Bas, Barcelona-Madrid, 1848 [1870]).

Martínez-Rodríguez, Susana, History of Corporations in Spain in the 20 $0^{\text {th }}$ Century: Towards Europe, en WeLLs, Harwell, Research Handbook on the History of Corporate and Company Law (Chelthenham, 2018), pp. 298-322.

-Creating the sociedad de responsabilidad limitada: The Use of Legal Flexibility in the Spanish Company Law, 1869-1953, en Business History Review, 90/2 (2016), pp. 227-249. 
McAuliffe, Karen, Precedent at the Court of Justice of the European Union: The Linguistic, en Aspect en Current Legal Issues, 15 (2013), pp. 483-493 [https://www.openaccessgovernment.org/linguistic-precedent/66866/]

MenÉndez, Aurelio. Sobre la moderna Escuela Española de Derecho mercantil (Madrid, [1993] 2016).

Navarro, Fausto, La configuración de la sociedad limitada a través de la práctica notarial, en Revista de Derecho Privado, 26 (1942), pp. 24-43.

$N^{\circ} 233$, Tribunal Supremo, 19 junio de 1952. Casación por infracción de ley. Principios Generales en Jurisprudencia Civil. Colección completa de las sentencias dictadas por el Tribunal Supremo (Madrid, 1953), XXVI, pp. 321-333.

$N^{o}$ 42, Tribunal Supremo, 6 mayo de 1920. Casación por infracción de ley. Cumplimiento del contrato de contraventa en Jurisprudencia Civil. Colección completa de las sentencias dictadas por el Tribunal Supremo (Madrid, 1923), LXVIII, pp. 245-249.

$N^{\circ}$ 58, Tribunal Supremo, 18 febrero 1948. Recurso de casación por infracción de ley. Sociedades de responsabilidad limitada: su asimilación al régimen de las Sociedades personalistas en Jurisprudencia Civil. Colección completa de las sentencias dictadas por el Tribunal Supremo (Madrid, 1950), XXI, pp. 531-534.

$N^{\circ}$ 94, Tribunal Supremo, 6 febrero 1929. Casación por infracción de ley. Sociedad Limitada en Jurisprudencia Civil. Colección completa de las sentencias dictadas por el Tribunal Supremo (Madrid, 1930), CLXXXVII, pp. 505-511.

Parisi, Francesco; DePoorter, Ben. Legal precedents and judicial discretion, en Rowley, Charles; SchNeIDER, Friedrich (eds.), Encyclopedia of public choice (Amsterdam, 2003), pp. 341-343.

Pelletier, Alejandro, Interpretación práctica de la ley de sociedades limitadas (Madrid, 1956).

Pérez Serrano, Nicolás. La proyectada reforma del Código de Comercio. Compañias Anónimas y limitadas, en Revista Derecho Privado, 158 (1927), pp. 3-19.

PiÑoL, Josep, Régimen jurídico de las sociedades de responsabilidad limitada, en Revista Jurídica de Cataluña, 70 (1953), pp. 525-528.

Polo, Antonio, Sociedades, en Revista de Derecho Privado, 302 (1942), pp. 245-249.

Riu y Periquet, Daniel. Anuario Financiero y de las Sociedades Anónimas de España (Madrid, 1918-1980).

Rodríguez Navarro, Manuel, Doctrinal mercantil del Tribunal Supremo (Madrid, 1948).

Ruiz Miguel Alfonso; Laporta, Francisco J., Precedent in Spain, en McCormick N., Deil; Summers, Robert S.; Goodhart, Arthur L., Interpreting Precedents. A comparative Studies (Londres, 1997), pp. 259-292.

Salvador Gullón, Pablo; SAlvador Gullón, Hilario, Fundación de la Sociedad Limitada, en Revista Jurídica de Cataluña, 70 (1953), pp. 529-577.

Sesión de Cortes, miércoles 24 de enero de 1883, Diario de las Sesiones de las Cortes. Congreso de los Diputados (1883), XXIX, pp. 593-617.

Taulet, Enrique, Sociedad de responsabilidad limitada. Conferencia desarrollada por D. pronunciada el 19 de enero de 1946 (Valencia, 1947).

Troper y Grzegorczyk (1997), Precedent in France, en McCormick N. Deil; Summers, Robert S.; Goodhart, Arthur L., Interpreting Precedents. A comparative Studies (Londres, 1997), pp. 103-141.

Vicente-Gella, Agustín, Aplicación a las compañias de responsabilidad limitada. Sentencia 3 de Julio de 1941, en Revista General de Legislación y Jurisprudencia, 86 (1941), pp. 625-628. 